\title{
Aggressive behaviour in Huntington's disease: a cross-sectional study in a nursing home population
}

\author{
R.S. Shiwach ${ }^{1}$ and V. Patel 2,3 \\ 'Department of Medical Genetics, Churchill Hospital, Headington, Oxford, UK \\ ${ }^{2}$ The Maudsley Hospital, London SE5 8AZ, UK \\ ${ }^{3}$ Current address: Section of Epidemiology and General Practice, Institute of Psychiatry, \\ London SE5 8AF, UK
}

Correspondence to: R.S. Shiwach, Deal Mental Health Centre, Bowling Green Lane, London Road, Deal, Kent CT14 9HF.

\begin{abstract}
We describe a cross-sectional study of aggressive behaviour in a sample of patients suffering from Huntington's disease in a residential nursing home. Data were obtained using the RAGE, a behaviourally oriented rating scale for measuring aggressive behaviour in cognitively impaired patients. Nursing staff rated 27 patients after a 3 day observation period. A third of the sample were rated to be at least mildly aggressive; the frequencies of some specific types of aggressive behaviour were high. In contrast, the frequency of injuries sustained and the use of restraints and medication for aggressive behaviour were low. Aggressive behaviour was found to be significantly related to the degree of functional impairment. These data are compared with those reported in a study using the RAGE to assess aggressive behaviour in a sample of elderly patients with dementia.
\end{abstract}

Keywords: Aggressive behaviour - Dementia - Huntington's disease

\section{INTRODUCTION}

Huntington's disease (HD) is an inherited neuropsychiatric disorder characterized by chorea and dementia and usually manifests in adult life (Hayden, 1981). Psychiatric disorders such as depressive illness, schizophrenia and behavioural problems are often seen in patients with varying frequency (Bruyn, 1968; James et al., 1969; Dewhurst, 1970; Wilson and Garron, 1979; Folstein and Folstein, 1983). These disorders can precede, accompany or follow the neurological symptoms (Bears, 1977). Often quoted behavioural changes include irritability, impatience, impulsiveness, being quarrelsome, moodiness and verbal and physical violence (Heathfield, 1967; Dewhurst et al., 1969; Bolt, 1970). This spectrum of behaviour leads to various familial and social pathology (Dewhurst et al., 1970; Oliver, 1970) and results in management problems at home. Due to behavioural problems and physical disability, a number of patients are managed in residential nursing homes; patients who become severely disturbed often need psychiatric hospitalization.

There have been few systematic studies of the incidence and types of aggressive behaviour in the setting of a residential nursing home for patients with $\mathrm{HD}$. A practical difficulty has been the relative rarity of the disorder and thus the lack of a suitable cohort of patients in an institutional

C1993 Rapid Communications of Oxford Ltd setting. This difficulty was overcome by studying the residents of the Sue Ryder nursing home (Stagenhoe Park, Hitchin, Hertfordshire, UK) which is a residential home for patients suffering from a range of progressive neurological disorders. The aim of our cross-sectional study was to describe the nature and frequency of aggressive behaviour in this sample of patients, and to examine the relationship of aggressive behaviour with functional impairment in HD. Ethical approval was given by the Central Oxford Research Ethics Committee as part of a wider project studying HD.

\section{METHODS}

The sample

The sample studied were all the patients residing in the Sue Ryder nursing home with $\mathrm{HD}(n=27)$. Patients referred to the Sue Ryder nursing home from surrounding counties are initially screened for any history of antisocial or violent behaviour and those with a severe history are occasionally rejected. Thus, in the 2 years before the study, three patients were refused admission from a total of 13 referrals. Nine patients with greater disability (as judged by staff on the basis of their mobility) were housed 
on the first floor and the less disabled were on the ground floor $(n=18)$.

\section{Data collection}

Behavioural ratings were made by nursing staff in the home over the 3 day period using the RAGE, a rating scale for measuring aggressive behaviour in patients suffering from dementia (Patel and Hope, 1992a). This rating scale consists of 23 items, of which 19 inquire about observable behaviour (for example, kicking, shouting, abusing, etc.), three items inquire about the consequences of aggressive behaviour (termed as the non-behavioural items) and one item asks for a global judgement of overall aggressiveness. The ratings are made at the end of a 3 day observation period. The 19 behavioural items are rated on the basis of a four-point frequency-based rating scale as follows:

0 : never occurred

1: occurred at least once in the past 3 days

2: occurred at least once every day in the past 3 days 3: occurred more than once every day in the past 3 days.

Two of the non-behavioural items were rated on the basis of the severity of injury inflicted on others or on one- self and the other item is a dichotomous (yes/no) rating whether the patient had been sedated or restrained as a consequence of aggressive behaviour. The item of overall aggressiveness was rated on a four-point scale of severity (not at all, mildly, moderately, severely).

The rating scale has been demonstrated to possess high inter-rater and test-retest reliability. It is sensitive to change, internally consistent and has clinical validity (Patel and Hope, 1992a). Clear instructions on the use of the rating scale were given to the raters who could be any member of the nursing staff who was on duty on at least two shifts over the 3 days. All raters were qualified psychiatric nurses with considerable experience in working with brain-damaged patients. The rating scale has been demonstrated to possess a greater inter-rater reliability when used in conjunction with a ward checklist, and thus, during the 3 days, a ward behaviour checklist which listed all the patients on each floor along one axis, and all the behavioural items of the rating scale along the other, was posted in the nursing office. Nurses on all shifts were asked to mark behaviours on the checklist whenever observed over the 3 days and the raters were instructed to use both the

TABLE I. Prevalence of various types of aggressive behaviour

\begin{tabular}{|c|c|c|c|c|c|}
\hline & \multicolumn{4}{|c|}{$\begin{array}{l}\text { Percentage of ratings for } \\
\text { each rating point }\end{array}$} & \multirow[t]{2}{*}{$\begin{array}{l}\text { Percentage } \\
\text { of positive ratings }\end{array}$} \\
\hline & 0 & 1 & 2 & 3 & \\
\hline Being uncooperative or resisted help & 66.7 & 29.6 & 0 & 3.7 & 33.3 \\
\hline Shouted, yelled or screamed & 74.1 & 18.5 & 3.7 & 3.7 & 25.9 \\
\hline $\begin{array}{l}\text { Been generally in a bad mood, irritable } \\
\text { or quick to fly off the handle }\end{array}$ & 74.1 & 18.5 & 3.7 & 3.7 & 25.9 \\
\hline $\begin{array}{l}\text { Been impatient or got angry if something } \\
\text { does not suit him/her }\end{array}$ & 77.8 & 22.2 & 0 & 0 & 22.2 \\
\hline Been demanding or argumentative & 81.5 & 11.1 & 7.4 & 0 & 18.5 \\
\hline Attempted to bite, scratch, pinch or spit at others & 88.9 & 7.4 & 0 & 3.7 & 11.1 \\
\hline Been angry with him or herself & 88.9 & 11.1 & 0 & 0 & 11.1 \\
\hline $\begin{array}{l}\text { Disobeyed ward rules, for example deliberately } \\
\text { passed urine outside the commode }\end{array}$ & 92.6 & 7.4 & 0 & 0 & 7.4 \\
\hline $\begin{array}{l}\text { Destroyed property or thrown things } \\
\text { around angrily }\end{array}$ & 92.6 & 7.4 & 0 & 0 & 7.4 \\
\hline Indulged in antisocial acts & 96.3 & 0 & 3.7 & 0 & 3.7 \\
\hline Been critical, sarcastic or derogatory & 96.3 & 3.7 & 0 & 0 & 3.7 \\
\hline Attempted to kick others & 96.3 & 0 & 0 & 3.7 & 3.7 \\
\hline Attempted to hit others & 96.3 & 0 & 0 & 3.7 & 3.7 \\
\hline Used an object to lash out or hurt someone & 96.3 & 3.7 & 0 & 0 & 3.7 \\
\hline Sworn or used abusive language & 100 & 0 & 0 & 0 & 0 \\
\hline $\begin{array}{l}\text { Threatened to harm or made statements to } \\
\text { scare others }\end{array}$ & 100 & 0 & 0 & 0 & 0 \\
\hline Been sexually offensive & 100 & 0 & 0 & 0 & 0 \\
\hline
\end{tabular}

44 Behavioural Neurology . Vol 6. 1993 
checklist and personal observations to make the final ratings.

The patients were not assessed quantitatively for dementia due to the advanced stage of the disease and the presence of dysarthria. Clinically, all the patients had a degree of dementia, and about half (13/27) had severe dementia as judged by the nurses. Only one patient had clear speech, four had coherent but slurred speech, four were virtually mute and the remainder had markedly slurred speech. All the patients were rated on the Functional Rating Scale (FRS; Shoulson and Fahn, 1979) by one of the authors (R.S.). Data for the ratings were obtained from the nursing staff. This scale is a useful functional indicator of the clinical state of a patient with HD particularly, as no single clinical scoring system encompasses the multitude of disabilities that the disease can inflict (Hayden, 1981). A note was also made of the use of psychotropic medication in each case.

\section{RESULTS}

\section{The sample}

Females outnumbered males in the sample (19:8). The mean age of the less disabled group was 47 years (range 22-61 years, S.D. 11.1 years). The mean age of onset of symptoms for this group $(n=18)$ was 41.5 years (range 19-62 years, S.D. 11.8 years) and the mean duration of neurological symptoms in the same group was 7 years. For the more disabled group $(n=9)$, mean age was 53.7 years (range 22-74 years, S.D. 15.5 years). The mean age of onset of symptoms was 42.3 years (range 18-66 years, S.D. 13.1 years) and the mean duration of neurological symptoms was 11.3 years.

\section{The frequency of various types of aggressive behaviour (Table I)}

A third of the patients had been uncooperative or resisted help and a quarter had yelled or screamed and were noted to be irritable or moody. One in five had pushed or shoved others, been demanding and argumentative and been impatient or become angry if something did not suit them. On the item for overall aggressiveness, seven patients were rated to be mildly aggressive, and three as being moderately aggressive. Fifty per cent of the female patients and $55 \%$ of the male patients showed some behavioural disturbance over the 3 day period. There was no significant difference between the total scores obtained by male and female patients (two-tailed $t$-test, $t=0.3$, d.f. $=25, p>0.05$ ).

\section{The prevalence of injuries and use of restraints/ medication}

There was a low incidence of injuries inflicted on others or on self, and no patient was sedated or restrained in order to
TABLE II. Correlation of individual items with the overall global impression

\begin{tabular}{|c|c|}
\hline & $\begin{array}{l}\text { Pearson's correlation coefficient } \\
\text { with two-tailed significance }\end{array}$ \\
\hline $\begin{array}{l}\text { Been demanding or } \\
\text { argumentative }\end{array}$ & $0.51, p<0.01$ \\
\hline Shouted, yelled or screamed & $0.69, p<0.001$ \\
\hline $\begin{array}{l}\text { Been uncooperative or resisted } \\
\text { help }\end{array}$ & $0.84, p<0.001$ \\
\hline $\begin{array}{l}\text { Been generally in a bad mood, } \\
\text { irritable or quick to fly off } \\
\text { the handle }\end{array}$ & $0.77, p<0.001$ \\
\hline $\begin{array}{l}\text { Been impatient or got angry if } \\
\text { something does not suit him/her }\end{array}$ & $0.33, p<0.05$ \\
\hline Pushed or shoved others & $0.32, p<0.05$ \\
\hline Been angry with him/herself & $0.34, p<0.01$ \\
\hline Attempted to kick others & $0.84, p<0.001$ \\
\hline Attempted to hit others & $0.78, p<0.001$ \\
\hline $\begin{array}{l}\text { Attempted to bite, scratch, pinch } \\
\text { or spit at others }\end{array}$ & $0.79, p<0.001$ \\
\hline Injuries inflicted on others & $0.77, p<0.001$ \\
\hline Injuries inflicted on self & $0.59, p<0.001$ \\
\hline Disobeyed ward rules & $0.32, p>0.05$ \\
\hline $\begin{array}{l}\text { Been critical, sarcastic or } \\
\text { derogatory }\end{array}$ & $0.26, p>0.05$ \\
\hline Indulged in antisocial acts & $0.18, p>0.05$ \\
\hline $\begin{array}{l}\text { Destroyed property or thrown } \\
\text { things around angrily }\end{array}$ & $0.10, p>0.05$ \\
\hline $\begin{array}{l}\text { Used an object to lash out or } \\
\text { hurt someone }\end{array}$ & $0.40, p>0.05$ \\
\hline
\end{tabular}

Four behavioural and one non-behavioural items were not rated at all during the 3 days and thus correlations could not be computed.

control their aggressive behaviour (although some patients were on small doses of neuroleptics for their involuntary movements).

\section{The correlation of aggression with functional rating scores}

The Pearson's correlation coefficient was 0.45 ( $p<0.01$, two-tailed significance).

The correlation of individual items with the overall global impression (Table II)

The correlation of individual items with the item on overall global impression was carried out using Pearson's correlation coefficient. Twelve items showed significant correlations, with the highest values being found for the items on physical aggression, irritability and being uncooperative or resisting help (for example, whilst being given a bath). In addition, the items on injuries sustained, 
although rare, also correlated highly with the overall global impression.

\section{DISCUSSION AND CONCLUSIONS}

This study has shown the presence of a mild to moderate degree of aggressive behaviour in a third of a sample of patients with HD living in a residential nursing home. These figures contrast with the $59 \%$ of out-patients suffering HD rated to be aggressive on the basis of ratings made on the Overt Aggression Scale (Yudofsky et al., 1986). However, in the latter study (Burns et al., 1990), relatives were asked about "aggressive outbursts" over an unspecified period of time retrospectively, as compared to precise observations of behaviour over 3 days in our study. Thus, the higher reported prevalence of aggressive behaviour in the Burns et al. study could be due to a combination of a longer period of observation and the fact that relatives were used as informants in a retrospective report. Moreover, the lower frequency observed in our sample could also be because it was biased (due to the selection procedures of the nursing home). The frequency of certain types of behaviour, such as being uncooperative or resisting help, being irritable, shouting, yelling or screaming, being impatient, demanding or argumentative and shouting and pushing or shoving others was high. In comparison, injuries were rare as were most types of physically aggressive behaviour, and medication or restraints were never used in order to control aggressive behaviour.

We also found a weak, though statistically significant, correlation between functional ratings and the severity of aggressive behaviour. This finding is similar to that of Stewart et al. (1987) who attribute the high levels of aggression in their sample of nursing home residents to their high degree of physical impairment. However, a comparison of the more and less disabled groups (as classified by the nursing staff on the basis of mobility) revealed no significant difference in aggressive behaviour $(t=1.9$, d.f. $=25, p>0.05)$. While the judgement of level of disability was based on the mobility of subjects, FRS ratings took into account a wider range of activities of daily living and thus aggressive behaviour in our study was more closely related with multiple impairments rather than simple impairment of mobility. It is possible that at a certain critical late stage in the illness, the reduced mobility and the presence of dementia decrease the overall frequency of aggressive behaviour.

The correlation of individual items with the overall global impression item gives an indication of the strength of the relationship of individual behaviours with the construct of aggression as perceived by the nursing staff who completed the ratings. The items which show significant correlations can be organized into three categories:

(1) Irritability is a recognized feature of HD (Folstein et al., 1987) and has been defined by Galbraith (1985) as a "fuming state characterized by reduced verbal control over temper which usually results in irascible, verbal and behavioural outbursts, although the mood may be present without any observed manifestations". In our study, irritability was seen in a quarter of the sample.

(2) Physically aggressive behaviours include kicking, hitting, biting, scratching, pinching and spitting at others. The high correlations despite the lower prevalence of such behaviours (compared with verbal aggressive behaviour) are a clear reminder that such behaviour is a strong determinant of the overall impression of aggressive behaviour. (3) Being uncooperative and resisting help poses considerable problems for carers and is particularly apparent during the activities of daily care, such as bathing and feeding. Behaviours such as shouting and being demanding or argumentative were frequently associated with such activities of daily care.

Our data were compared with those obtained from a sample of in-patients with dementia in an old age ward using the RAGE (Patel and Hope, 1992b). The overall frequency of aggressive behaviour is lower in our sample of patients ( $30 \%$ vs $45 \%$ ), but this could be partly explained by the selection procedure; thus, one would expect a hospital population to show greater degrees of behavioural disturbance than a nursing home population. What is significant, though, is the remarkable similarity in the order of frequency of individual behaviours, with being uncooperative, shouting, yelling or screaming, being impatient and demanding and argumentative being the commonest behaviours encountered in both groups. This qualitative similarity between the two groups of patients lends support to Brown and Marsden's (1988) contention that there is no neat distinction between cortical (Alzheimer's disease) and subcortical dementia (HD).

In conclusion, we have presented the findings of a cross-sectional observational rating of aggressive behaviour in a nursing home population of patients suffering from HD. At least a third of all patients were found to be aggressive over a 3 day period. The main findings of the study are:

(1) Aggressive behaviour was observed in a third of the sample; however injuries were rare as was the use of sedation.

(2) There was no relationship between aggressive behaviour and sex of the patient.

(3) There is a relationship between multiple impairments (as measured by the FRS) and severity of aggressive behaviour but not with mobility alone (as assessed by nurses).

(4) Some types of behaviour are especially common, and there is a qualitative similarity in the nature of aggressive behaviour found in our sample and that reported in elderly patients with dementia.

(5) Some behaviours correlate highly with the overall 
global impression of aggressive behaviour as assessed by nurses suggesting that these behaviours have a greater contribution to the overall construct of aggression.

There are two main limitations to this study; first, the sample is not representative of HD in general. To achieve a representative sample, one would need to study patients based in the community and in institutional care. In addition, the RAGE is not validated for use in the community and thus our data would have been mismatched. Secondly, this is a cross-sectional study which provides no information on aetiological or naturalistic factors; since Huntington's disease has a chronically progressive course with a fluctuating clinical picture (Cameron and Venters, 1967; Reed et al., 1958) a longitudinal prospective study using a behaviourally oriented rating scale would be the next logical step.

\section{Acknowledgements}

We would like to thank Sister Sue Flind and her colleagues at the Sue Ryder home in Hitchin, Herts for their full participation in this study. We are also grateful to Dr Watts for his comments. R.S. was on a Wellcome Grant and V.P. was on a Rhodes Scholarship when this study was carried out.

\section{REFERENCES}

Bears D (1977) Position paper on emotional and behavioural changes in Huntington's disease. In: Report Commission for the Control of Huntington's Disease and its Consequences. DHEW Publication (NIH), Vol. 3, Part 1, pp. 78-1503, Washington, DC.

Bolt JMW (1970) Huntington's chorea in the west of Scotland. British Journal of Psychiatry, 116, 259-270.

Brown RG and Marsden CD (1988) Subcortical dementia: The neuropsychological evidence. Neuroscience, 25, 363-387.

Bruyn G (1986) Huntington's chorea: Historical, clinical and laboratory synopsis. In: Handbook of Clinical Neurology, Vol. 6 (eds P Vinken and G Bruyn). North Holland, Amsterdam.

Burns A, Folstein S, Brandt J et al. (1990) Clinical assessment of irritability, aggression and apathy in Huntington's and Alzheimer's disease. Journal of Nervous and Mental Disease, 178, 20-26.

Cameron D and Venters GA (1967) Some problems in Huntington's Chorea. Scottish Medical Journal, 12, 152-156.

Dewhurst K (1970) Personality disorder in Huntington's disease. Psychiatric Clinics, 3, 221-229.
Dewhurst K, Oliver J, Trick K et al. (1969) Neuropsychiatric aspects of Huntington's chorea. Confinia Neurologica, 31, 258-268.

Dewhurst K, Oliver JE and McKnight AL (1970) Sociopsychiatric consequences of Huntington's disease. British Journal of Psychiatry, 116, 255-258.

Folstein S and Folstein M (1983) Psychiatric symptoms of Huntington's disease: Recent approaches and findings. Psychiatric Developments, 2, 193-206.

Folstein S, Chase G, Wahl W et al. (1987) Huntington's disease in Maryland. American Journal of Human Genetics, 41, 168-179.

Galbraith S (1985) Irritability. British Medical Journal, 291, 1668.

Hayden MR (1981) Huntington's Chorea. Springer-Verlag, New York.

Heathfield K (1967) Huntington's chorea: Investigation into the prevalence of this disease in the area covered by the North East Metropolitan Hospital Board. Brain, 90, 203-232.

James W, Mefferd R and Kimbell I (1969) Early signs of Huntington's chorea. Diseases of the Nervous System, 30, 558-559.

Oliver JE (1970) Huntington's chorea in Northamptonshire. British Journal of Psychiatry, 166, 241-253.

Patel V and Hope RA (1992a) A rating scale for aggressive behaviour in the elderly (the RAGE). Psychological Medicine, 22, 211-221.

Patel V and Hope RA (1992b) Aggressive behaviour in elderly psychiatric inpatients. Acta Psychiatrica Scandinavica, 85, 131-135.

Reed TE, Chandler JH, Hughes EM et al. (1958) Huntington's chorea in Michigan: demography and genetics. American Journal of Human Genetics, 10, 201-225.

Shoulson I and Fahn H (1979) Huntington's disease: Clinical care and evaluation. Neurology, 29, 1-3.

Stewart JT, Mounts ML and Clark RL (1987) Aggressive behaviour in Huntington's disease: Treatment with Propanalol. Journal of Clinical Psychiatry, 48, 106-108.

Wilson RS and Garron DC (1979) Cognitive and affective aspects of Huntington's disease. In: Advances in Neurology (eds TN Chase, NS Wexler and A Barbeau). Raven Press, New York.

Yudofsky SC, Silver JM, Jackson W et al. (1986) The Overt Aggression Scale for the objective rating of verbal and physical aggression. American Journal of Psychiatry, 143, 35-39.

(Received 15 March 1993; accepted 2 April 1993) 


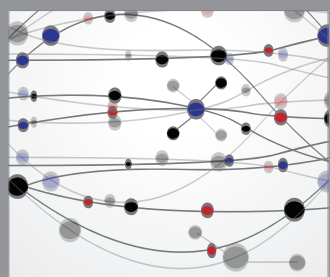

The Scientific World Journal
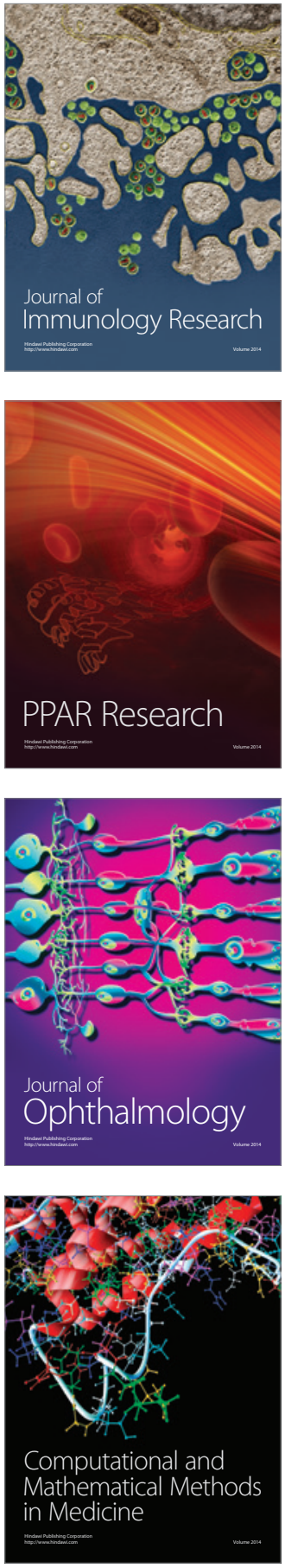

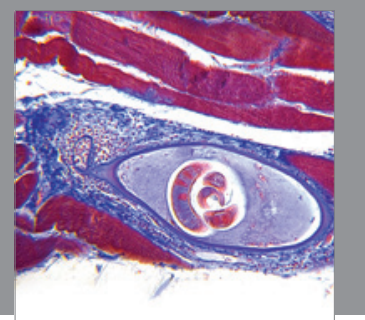

Gastroenterology

Research and Practice
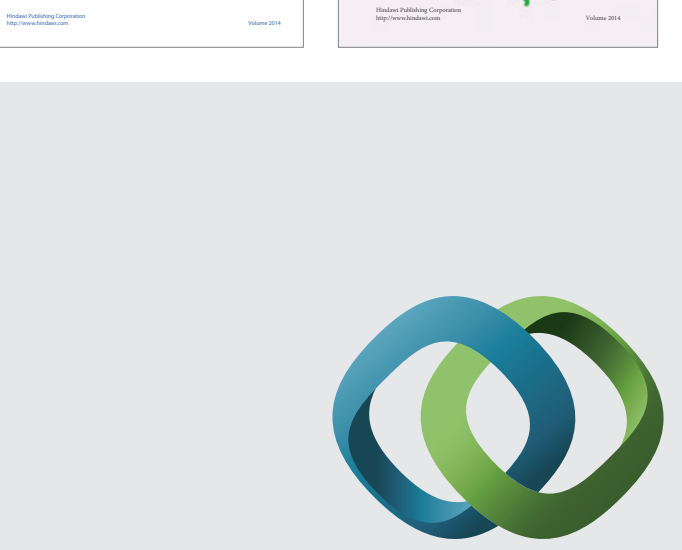

\section{Hindawi}

Submit your manuscripts at

http://www.hindawi.com
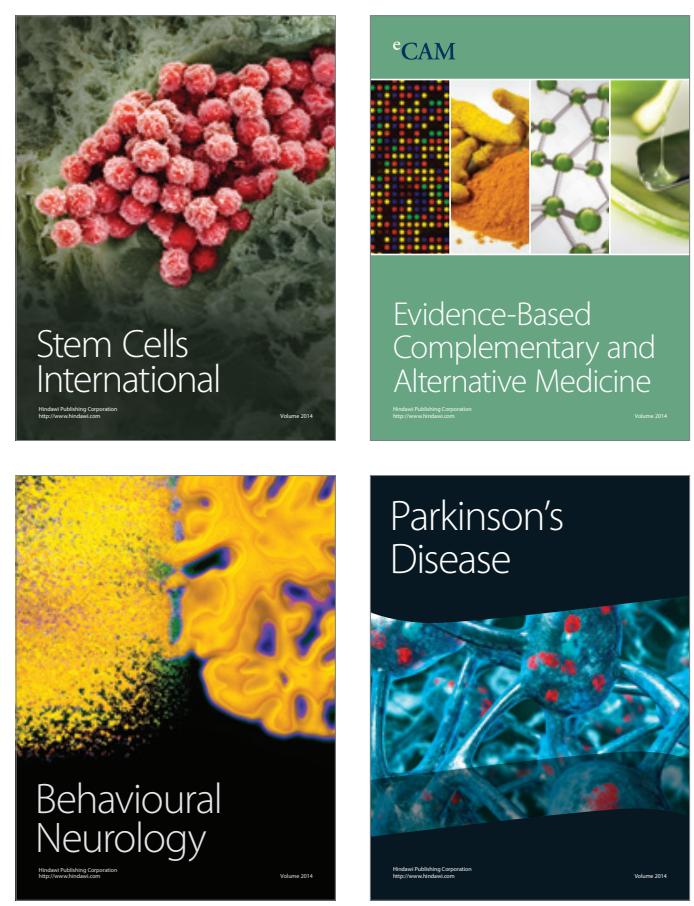

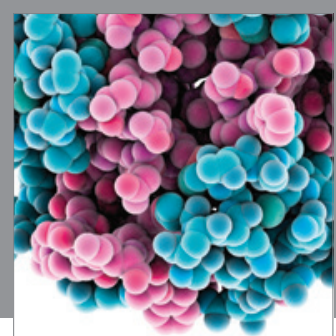

Journal of
Diabetes Research

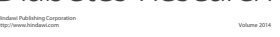

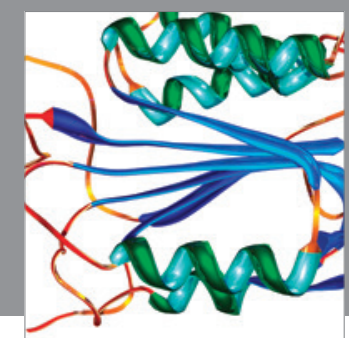

Disease Markers
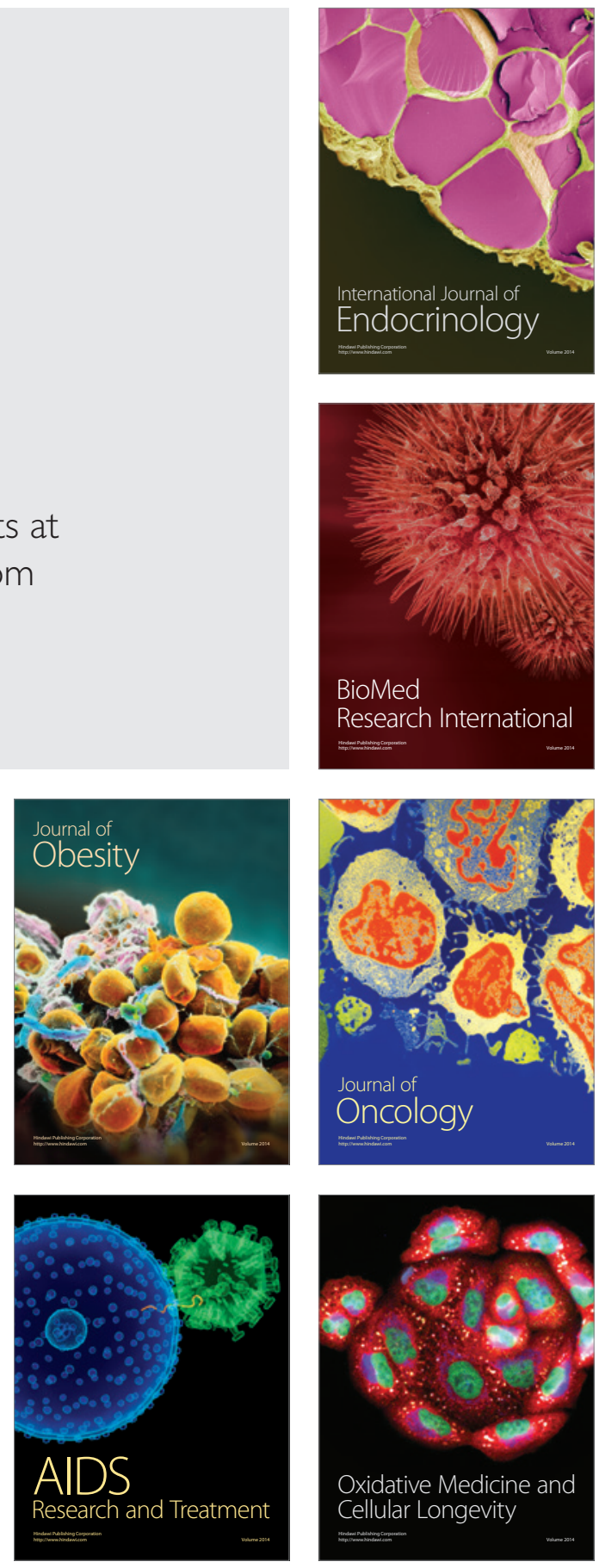